\title{
Psychosocial outcome for the survivors of severe blunt head injury: the results from a consecutive series of 100 patients
}

\author{
R L TATE, * J M LUlhaM, * G A BROE, $\dagger$ B STRETTleS, * A PFAFF* \\ From the Lidcombe Hospital, ${ }^{*}$ and the University of Sydney, $\dagger$ Sydney, Australia
}

SUMMARY A consecutive series of 100 severely blunt head injured subjects was followed up six years after trauma and the level of psychosocial reintegration was determined for 87 subjects. Three- \& quarters of the series were classified as demonstrating major disability, having either a Poor $\vec{\circ}$ Reintegration (33\%) or a Substantially Limited Reintegration $(43 \%)$; the remaining one-quarter of the series attained a Good Reintegration. The level of reintegration was related to the Glasgow $\vec{\omega}$ Outcome Scale classification, although a one-to-one correspondence between the Glasgow Outcome Scale and the Psychosocial Disability Scale was not found: each of the Moderate Disability and Good Recovery groups was fairly evenly divided between a better and worse level of reintegration. Specific in aspects of the subjects' psychosocial reintegration in employment, interpersonal relationships, $\vec{\circ}$ functional independence, social contacts and leisure interests are described and the implications of the findings for the provision of extended care services to meet the long term needs are discussed.

A feature of recovery from severe degrees of blunt head injury is that the ultimate level of outcome varies markedly between individuals from severe disability to good recovery. ${ }^{1}$ This variability is also observed for specific impairment areas in neurophysical, cognitive and behavioural functions. ${ }^{2-6}$

To date, reports on subjects' abilities to resume the premorbid lifestyle have largely focused on documenting the disabilities for individual components of psychosocial functioning, such as employment, interpersonal relationships and leisure pursuits. ${ }^{7-9}$ These studies have highlighted the bleak outcomes in the specific psychosocial functions for the majority of victims. Few studies, however, have reported on psychosocial outcome in overall terms (exceptions being Bond's ${ }^{1011}$ original correlational study and Dodwell' ${ }^{12}$ investigation).

There is a current requirement for more detailed information regarding psychosocial reintegration after severe blunt head injury. First, no reliable data are available concerning the frequencies of both the

Correspondence to: Robyn Tate, Neuropsychology Department, Lidcombe Hospital, Joseph Street, Lidcombe 2141, NSW, Australia.

Received 21 October 1988 and in revised form 9 March 1989. Accepted 3 June 1989 presence as well as the levels of severity of overat psychosocial disability. This type of information is required to identify the needs of this group and henee to develop and provide services to cater for sucti. disabilities as they may experience. Second, given the range of the types and degrees of permanent disabilities, detailed information is required for broad subgroups of the head injured, such as those afforded by the Glasgow Outcome Scale $^{13}$ classification, because the long term needs of a subject classified as severe disability, for example, may well be different from those of a subject classified as moderate disability.

The aims of the present report are to (1) examine the extent of overall psychosocial disability in a geographically-based, consecutive series of severe blunt head injured victims in the outcome stage; and (2) compare the psychosocial outcomes of subgroups classified according to the Glasgow Outcome Scale, both for the overall level of reintegration as well as specific aspects of psychosocial functioning.

\section{Method}

\section{Subjects}

The consecutive series comprised the first 100 blunt head injured patients admitted to a regional unit in Lidcombe Hospital for the rehabilitation of severe head injured adults. The subjects were followed up, on average, at six years post- 
trauma (range 3.4 to 9.7 years): six subjects were unable to be located and a further seven were deceased, leaving a sample of 87 subjects for interview, who were, on average, 30 years of age (range 19 to 53 years). A close relative (mainly parent $(61 \%)$ or spouse $(29 \%))$ of the head injured subjects was also interviewed.

The subject characteristics parallel the epidemiological features of head injury, substantiating the representativeness of the series. The sex ratio males:females was approximately $3: 1$ and the average age at injury was 23.9 years (standard deviation 6.85 years, range 15 to 45 years).

The injury data for the series, presented in table 1, demonstrate the extremely severe degrees of injury of the group: the average length of unresponsiveness to verbal command was approximately three weeks and the duration of post-traumatic amnesia (PTA) was almost three months. These indices of injury severity were determined by the neurologist (GAB) under whose care the subjects had been admitted for rehabilitation. Each subject's medical record for the acute stages of hospitalisation was examined retrospectively by GAB, the majority of subjects having received their injuries prior to systematic use of the Glasgow Coma Scale in the acute stages.

The ranges were large, both for length of unresponsiveness and duration of PTA. Two of the three subjects who were conscious on first admission to hospital had comminuted depressed fractures, and all three had a duration of PTA between six and eight weeks. Duration of PTA exceeded one week in $98 \%$, and one month in $74 \%$ of the series.

The injuries for three-quarters of the series were the result of motor car or motor cycle accidents. The mechanism of the injury was blunt head trauma (as opposed to a penetrating head injury) for all subjects: 48 subjects received a closed head injury, 20 subjects received an open head injury and 19 subjects required a neurosurgical procedure following an initial closed head injury ( 17 of whom had craniotomy and/or burr holes for suspected intracranial haematoma).

Table 1 Injury data for head injured series $(n=87)$

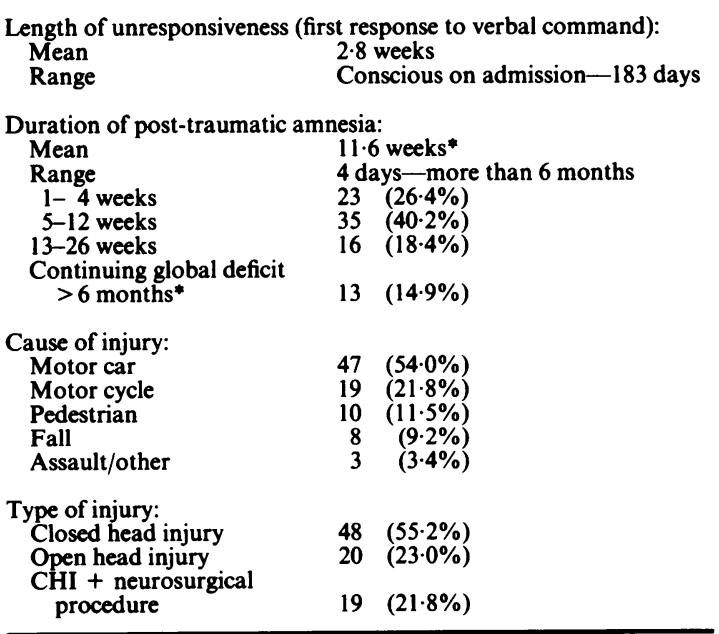

* Subjects with continuing and profound deficit persisting for more than 6 months were taken as equal to 6 months for the purpose of determining the mean score for duration of PTA.
The background characteristics of the head injured subjects are presented in table 2. As a group, the subjects received limited formal schooling and most had not engaged in further education upon leaving school, although one-third of the series attended college courses, predominantly in the skilled trades and clerical areas. The young age of the subjects ( 30 of the 87 subjects were less than 20 years at injury) indicated that their occupational status was probably not fully determined. All subjects, save eight $(9 \cdot 2 \%)$, were either employed (77 subjects) or school students (two subjects) at the time of injury.

One-third of the series ( 31 subjects) was married or in a de facto relationship at injury. The subjects were a healthy group premorbidly, of the average ranges of intelligence and most were socially well adjusted. Eleven subjects (12.6\%) were classified as premorbidly socially maladjusted: four subjects had criminal records and previous gaol sentences, three subjects had delinquent behaviour which had resulted in noncustodial sentences, three subjects had substance abuse (one subject with heroin addiction and two subjects with excessive alcohol consumption) and the final subject had a criminal record as well as a history of heroin and barbiturate abuse.

Notwithstanding the severity of the initial injuries, at the time of follow up approximately half the series was classified by the neurologist as having attained a Good Recovery on the Glasgow Outcome Scale. Of the remaining subjects, 26 were classified as Moderate Disability and 16 as Severe Disability. While the three outcome groups were similar with respect to subject characteristics, such as age at follow-up and the sex ratio, indices of severity of initial injury in particular were markedly different between the groups, as shown in table 3 . There were also proportionately more closed head injuries in the Good Recovery group, although the Contingency test was not significant $\left(\chi^{2}=7 \cdot 05, \mathrm{p}>\right.$ 0.05).

\section{Materials}

Each head injured subject and relative was separately administered a structured interview which examined the

Table 2 Background characteristics of the head injured series $(n=87)$

\begin{tabular}{|c|c|c|}
\hline $\begin{array}{cc}\text { Years of schooling: } \\
\text { Mean } & 9 \cdot 3 \\
\text { Range } & 5-12\end{array}$ & $\begin{array}{l}\text { Further education: } \\
\text { Nil } \\
\text { On-the-job training } \\
\text { College/University }\end{array}$ & $\begin{array}{r}51 \\
6 \\
30\end{array}$ \\
\hline $\begin{array}{l}\text { Premorbid IQ estimate:* } \\
\text { Low average or less } \\
\text { Average } \\
\text { High average or above }\end{array}$ & $\begin{array}{ll}15 & (17 \cdot 2 \%) \\
42 & (48 \cdot 3 \%) \\
16 & (18 \cdot 4 \%)\end{array}$ & \\
\hline $\begin{array}{l}\text { Occupational status at injury: } \\
\text { Professional/Managerial } \\
\text { Clerical/Sales } \\
\text { Skilled } \\
\text { Semi-skilled } \\
\text { Unskilled } \\
\text { Unemployed } \\
\text { School students }\end{array}$ & $\begin{array}{rr}6 & (6 \cdot 9 \%) \\
11 & (12 \cdot 6 \%) \\
13 & (14.9 \%) \\
33 & (37.9 \%) \\
14 & (16 \cdot 1 \%) \\
8 & (9 \cdot 2 \%) \\
2 & (2 \cdot 3 \%)\end{array}$ & \\
\hline "Social maladjustment" & $11 \quad(12 \cdot 6 \%)$ & \\
\hline
\end{tabular}

*IQ estimate was based on neuropsychological examination. No information was available for 14 subjects. 
injured person's lifestyle in a range of areas, including employment, interpersonal relationships, functional independence, social contacts and leisure interests. The relatives' responses were used for data analysis in the present report to ensure that results were obtained for the whole group and that they were valid. In the examination of a consecutive series, the deficits of some subjects (those with severe aphasia or cognitive deterioration in particular) serve either to preclude administration of the interview or the resulting data are unreliable and invalid. For five subjects for whom a relative could not be obtained, their own data were used (each subject having good neuropsychological skills).

In addition to the data collected from the structured interview, the level of overall psychosocial disability was determined for each subject. The classification was made on the basis of three areas of functioning: (1) vocational and avocational pursuits; (2) the ability to form and maintain significant interpersonal relationships; and (3) functional independence (that is, the ability to live independently). Clinical ratings by JML and BS, social worker and community nurse respectively, were used for classification (refer to the Appendix for scoring and classification procedures for the Psychosocial Disability Scale). Three categories of psychosocial outcome were adopted: Good Reintegration, Substantially Limited Reintegration and Poor Reintegration.

\section{Results}

\section{Overall psychosocial disability}

The level of overall psychosocial reintegration was Good for $24 \cdot 1 \%$ of the series (21 subjects), Substantially Limited for $42.5 \%$ (37 subjects) and Poor for $33.3 \%$ (29 subjects). Table 4 presents the psychosocial outcomes for the head injured series as a whole and the three Glasgow Outcome Scale groups (Good Recovery, Moderate Disability and Severe Disability). The Contingency test between the Glasgow Outcome Scale and the Psychosocial Disability Scale was highly significant.

One-way analyses of variance were performed on the data pertaining to severity of the initial injury and the level of psychosocial outcome as measured by the Scale. The main effects were highly significant, both for the number of days of unresponsiveness $(F(2,84)$ $=17 \cdot 30, \mathrm{p}<0.001)$ and the number of days duration of PTA $(\mathrm{F}(2,84)=34 \cdot 18, \mathrm{p}<0.001)$, indicating the
Table 3 Subject and injury data for head injured subjects grouped according to the Glasgow Outcome Scale: Good Recovery (GR), Moderate Disability (MD), and Severe Disability (SD)

\begin{tabular}{|c|c|c|c|}
\hline & $\begin{array}{l}G R \\
(n=45)\end{array}$ & $\begin{array}{l}M D \\
(n=26)\end{array}$ & $\begin{array}{l}S D \\
(n=16)\end{array}$ \\
\hline $\begin{array}{l}\text { Mean age at follow-up: } \\
\text { Standard deviation } \\
\text { Range }\end{array}$ & $\begin{array}{c}29 \cdot 3 \\
7 \cdot 08 \\
19-53\end{array}$ & $\begin{array}{c}31 \cdot 4 \\
8 \cdot 25 \\
19-48\end{array}$ & $\begin{array}{c}29 \cdot 9 \\
6 \cdot 83 \\
20-42\end{array}$ \\
\hline $\begin{array}{l}\text { Sex: Males } \\
\text { Females }\end{array}$ & $\begin{array}{l}33 \\
12\end{array}$ & $\begin{array}{r}21 \\
5\end{array}$ & $\begin{array}{r}12 \\
4\end{array}$ \\
\hline
\end{tabular}

Length of unresponsiveness to verbal command (days): Mean

Standard deviation

$\begin{array}{ll}5.3 & 19 \cdot 8 \\ 7.32 & 19.98\end{array}$

$\begin{array}{ll}7.32 & 19.98\end{array}$

Range

0-35 1-74

44.68

Mean duration of PTA (days):

Standard deviation

Range

$\begin{array}{lll}40 \cdot 8 & 99 \cdot 3 & 165 \cdot 1 \\ 26 \cdot 39 & 50 \cdot 32 & 32 \cdot 66 \\ 4-134 & 6->183 & 90->183\end{array}$

Type of injury:

Closed head injury

Open head injury

Closed head injury + neurosurgical procedure

\begin{tabular}{rrr}
30 & 11 & 7 \\
8 & 9 & 3 \\
7 & & 6 \\
\hline
\end{tabular}

importance of the initial severity of the injury in determining psychosocial disability.

\section{Head injured subgroups:}

Specific aspects of psychosocial outcome for the three head injured subgroups are presented in table 5.

(i) Good Recovery Group $(n=45)$ :

Less than half the Good Recovery subjects $(20$ subjects, accounting for $44.4 \%$ of the group) attained an overall Good Reintegration; for the majority, 25 subjects, the level of psychosocial reintegration was Substantially Limited.

The area in which the Good Recovery group fared best was functional independence, where all subjects, save three, were able to live independently, although 13 of these 42 independent subjects required emotional supports in order to do so. All Good Recovery subjects were independent in self care activities and

Table 4 Level of psychosocial reintegration

\begin{tabular}{|c|c|c|c|c|}
\hline & \multicolumn{4}{|c|}{ Glasgow Outcome Scale } \\
\hline & $\begin{array}{l}\text { Good Recovery } \\
(n=45)\end{array}$ & $\begin{array}{l}\text { Moderate Disability } \\
(n=26)\end{array}$ & $\begin{array}{l}\text { Severe Disability } \\
(n=16)\end{array}$ & $\begin{array}{l}\text { Head injured } \\
(n=87)\end{array}$ \\
\hline $\begin{array}{l}\text { Good } \\
\text { Substantially Limited } \\
\text { Poor }\end{array}$ & $\begin{aligned} 21 & (44 \cdot 4 \%) \\
25 & (55 \cdot 6 \%) \\
0 & \end{aligned}$ & $\begin{aligned} 1 & (3 \cdot 8 \%) \\
12 & (46 \cdot 2 \%) \\
13 & (50 \%)\end{aligned}$ & $\begin{array}{rr}0 & \\
0 & \\
16 & (100 \%)\end{array}$ & $\begin{array}{ll}21 & (24 \cdot 1 \%) \\
37 & (42 \cdot 5 \%) \\
29 & (33 \cdot 3 \%)\end{array}$ \\
\hline
\end{tabular}

$\chi^{2}=63.3 ; p<0.0001 ;$ contingency coefficient $=0.65$. 
Table 5 Specific aspects of psychosocial reintegration for Good Recovery (GR), Moderate Disability (MD), and Severe Disability (SD) (for explanation of levels 1-3 refer to Appendix)

\begin{tabular}{|c|c|c|c|}
\hline & $\begin{array}{l}G R \\
(n=45)\end{array}$ & $\begin{array}{l}M D \\
(n=26)\end{array}$ & $\begin{array}{l}S D \\
(n=16)\end{array}$ \\
\hline $\begin{array}{l}\text { Vocational/avocational: } \\
\text { Level } 1 \\
\text { Level } 2 \\
\text { Level } 3\end{array}$ & $\begin{array}{r}25 \\
15 \\
5\end{array}$ & $\begin{array}{r}1 \\
11 \\
14\end{array}$ & $\begin{array}{r}0 \\
1 \\
15\end{array}$ \\
\hline $\begin{array}{l}\text { Significant relationships: } \\
\text { Level } 1 \\
\text { Level } 2 \\
\text { Level } 3\end{array}$ & $\begin{array}{r}25 \\
20 \\
0\end{array}$ & $\begin{array}{r}3 \\
20 \\
3\end{array}$ & $\begin{array}{r}0 \\
3 \\
13\end{array}$ \\
\hline $\begin{array}{l}\text { Functional independence } \\
\text { Level } 1 \\
\text { Level } 2 \\
\text { Level } 3\end{array}$ & $\begin{array}{r}42 \\
3 \\
0\end{array}$ & $\begin{array}{r}4 \\
21 \\
1\end{array}$ & $\begin{array}{r}0 \\
1 \\
15\end{array}$ \\
\hline $\begin{array}{l}\text { Social contacts: } \\
\text { Adequate } \\
\text { Limited } \\
\text { Socially isolated }\end{array}$ & $\begin{array}{r}23 \\
9 \\
13\end{array}$ & $\begin{array}{r}9 \\
6 \\
11\end{array}$ & $\begin{array}{r}1 \\
3 \\
12\end{array}$ \\
\hline $\begin{array}{l}\text { Leisure interests: } \\
\text { Specific interests } \\
\text { Vague social network } \\
\text { Inadequate: } \\
\text { (i) "filling in time" } \\
\text { (ii) nil }\end{array}$ & $\begin{array}{r}25 \\
11 \\
8 \\
1\end{array}$ & $\begin{array}{r}12 \\
2\end{array}$ & $\begin{array}{l}5 \\
0\end{array}$ \\
\hline
\end{tabular}

mobility. More than one-quarter of the Good Recovery group (13 subjects) lived with their parent(s) (11 of these subjects had lived with parents prior to the injury) and when this group was compared with the 19 Good Recovery subjects living with a partner at follow-up, the subjects living with a partner had attained a significantly better psychosocial reintegration than the subjects living with their parents $\left(\chi^{2}=\right.$ $8 \cdot 29, \mathrm{p}<0 \cdot 005$ ).

With one exception, the 13 premorbidly single subjects who were married or in a de facto relationship at follow up were from the Good Recovery group, as were (with three exceptions) each of the 28 subjects in the series classified as having adequate abilities to form and maintain significant interpersonal relationships. Marital breakdown as such did not occur as frequently in the Good Recovery group as in the other groups (five of the 12 pretrauma marriages had broken down) and in the six pretrauma marriages remaining at follow up (one subject's husband was killed in the car accident in which she received her head injuries) there was also not the degree of dependency that was a feature of the other disability groups.

Yet, although no Good Recovery subject was classified as being unable to form significant interpersonal relationships, almost half the group ( 20 subjects) was classified as having major difficulties maintaining these relationships, such major difficulties being above and beyond the difficulties generally experienced in everyday living. These difficulties were reflected in many subject's histories after injury: of the 33 Good Recovery subjects who were single premorbidly, 21 subjects remained single at follow-up: although three of the 21 subjects had been married in the interim and a further two subjects had a partner but were not cohabiting, ten of the remaining 16 Good Recovery subjects had not been in a relationship since the injury, which had occurred, on average, six years previously.

With one exception, full time, paid, employment on the open market was limited to Good Recovery subjects. In all, 19 subjects in the series (18 from the Good Recovery group) were fully employed at followup. A further six Good Recovery subjects had other types of work (part-time, casual and home duties) and 11 subjects were unemployed, ten of these subjects having worked at some stage following the injury. Yet, almost one quarter of the Good Recovery group (ten subjects) was not working and was in receipt of the Invalid Pension.

All, save three, of the subjects who were employed full time either had a drop in occupational status (six subjects) or experienced difficulties with their work skills (ten subjects); three of these ten subjects had moved laterally within the same occupational status to more sheltered duties. Seven of the 19 subjects in full time employment had the same employer as before the injury and all subjects, save three, had been working in their current job for at least 12 months.

The subjects from the Good Recovery group were not infrequently socially isolated (13 subjects) and had poorly defined leisure interests ( 20 subjects). Overall, two-thirds of this group (30 subjects) was engaged in work (full time, part-time, home duties or sheltered work) or had substituted an avocational programme. One-third of the Good Recovery group (15 subjects), however, had no such involvement, and these subjects led aimless and socially isolated lives, which were almost totally devoid of focused and planned activity.

(ii) Moderate Disability Group $(n=26)$ :

The overall psychosocial outcome was Poor for half the Moderate Disability group (13 subjects), 12 subjects were classified as having Substantially Limited Reintegration and one as Good.

Although only one of the 26 subjects was functionally dependent requiring custodial care, $80 \%$ of this group (21 subjects) required supported and supervised living arrangements, in spite of all subjects being independent in self care activities and only six subjects requiring aides for mobility. A large proportion of the group, 11 subjects, lived with their parents and five of the six subjects who lived with a partner required supervision and substantial support from the partner.

Most Moderate Disability subjects were classified as either unable to form significant interpersonal 
relationships (three subjects) or demonstrated major difficulties in their abilities to do so (20 subjects). Seven of the 11 pretrauma marriages had broken down; in three of these seven cases the head injured subject was in a new relationship, with one cohabiting. Eleven of the 15 subjects classified as single prior to injury remained single without a partner at follow-up, and only one of these subjects had had a relationship since the injury.

One of the Moderate Disability subjects was employed. Of the nine subjects in the series who attended Sheltered Workshops at follow up, six were Moderate Disability subjects. For the remaining 19 Moderate Disability subjects who neither worked nor currently attended a Sheltered Workshop, 12 had attended a Sheltered Workshop at some stage following discharge from hospital, but had ceased attending, usually because of various dislikes of the workshop environments (mainly the disabilities of the other workers and the simple and repetitive nature of the work tasks). In only two of these 12 cases was there an adequate replacement of sheltered work with an avocational programme.

Almost half the group had specific leisure interests and/or adequate social contacts outside family. In fact, overall, half the Moderate Disability group (12 subjects) was engaged in some kind of work or in lieu had a network of avocational activities, interests and social groups in which they were actively involved. The other half of the Moderate Disability subjects, however, were similar to the corresponding one-third of the Good Recovery group: in addition to disabilities in areas such as work, interpersonal relationships and functional independence, they were also uninvolved in specific activities and hence opportunities to establish friendships and derive self esteem from the product of such activities and interests as they may pursue were extremely limited.

\section{(iii) Severe Disability Group $(n=16)$ :}

The overall psychosocial outcome was Poor for all subjects in the Severe Disability group. In terms of functional independence, no Severe Disability subject was able to live independently. With one exception, all subjects were classified as fully dependent upon others, requiring custodial care. In spite of the disability, however, half the group lived at home, with six of these eight subjects either dependent in the self care activities of feeding, bathing, toileting and dressing (four subjects) or requiring aides for mobility (two subjects). The remaining subjects, save one, lived in some kind of institution. The six subjects in the series $\mathbf{7 \%}$ ) who were placed in Nursing Homes were from the Severe Disability group: four were dependent in basic self care activities, and two subjects, although independent, required constant supervision because of neuropsychological impairments.
Each of the Severe Disability subjects was classified as permanently incapacitated for work, yet in spite of the resultant large amount of "spare time", leisure interests were generally nonexistent (seven subjects) or comprised activities which could only be described as "filling in time", such as "he walks and chats" (four subjects) and virtually all subjects were either socially isolated (12 subjects) or had substantially limited social contacts (three subjects). Only one Severe Disability subject attended a Sheltered Workshop.

Further, all subjects, save three, were classified as being unable to form significant interpersonal relationships. Whereas half the Severe Disability group was married or in a de facto relationship at the time of the injury, only three remained married at the time of follow up and in each case the spouse was, in reality, a caretaker. Seven of the remaining eight subjects who were single prior to the injury remained single and had not been in a relationship since the injury.

\section{Discussion}

The present study found that psychosocial consequences of severe head injury vary markedly between individuals: $24 \%$ were classified as having attained a Good Reintegration, $43 \%$ a Substantially Limited Reintegration, and 33\% a Poor Reintegration. Comparison of these findings with those of other studies is problematic, because frequency data for overall psychosocial outcome have not been reported to date.

It was encouraging that following such severe injuries one quarter of the present series can be described as achieving a good psychosocial reintegration, with the basic type of lifestyle expected of an average 30 year old. Nonetheless, the majority of the Good Reintegration subjects (who, with one exception, were also Good Recovery subjects) did not escape adverse psychosocial consequences from the injury, including difficulties with work skills, drop in occupational status, social isolation and/or they required emotional supports in order to live independently. In order to guard against overestimation of difficulties in the subjects' lifestyles, the present Psychosocial Disability Scale adopted a fairly liberal method of rating the specific areas, particularly for the best level of outcome (refer to Appendix). Thus, although the subjects classified as Good Reintegration have certainly made a successful psychosocial reintegration, particularly in comparison with the other head injured groups, it does not imply that "good" is synonymous with the full resumption of the premorbid lifestyle.

The levels of psychosocial reintegration for the remaining three-quarters of the series, however, indicate major disability. Psychosocial reintegration was substantially limited for $43 \%$ of the head injured 
series, although it was restricted to subjects with relatively better levels of recovery: half the Moderate Disability and $56 \%$ of the Good Recovery groups. It should be stressed that Substantially Limited Reintegration does not imply some degree of mild trouble or inconvenience in the resumption of the premorbid lifestyle. Rather, the activities, competencies, opportunities and achievements normally available to the average person are no longer options for subjects from this group and they are forced to accommodate to a very restricted lifestyle, dependent upon such family supports as are available.

Furthermore, for one third of the head injured series (all Severe Disability and half the Moderate Disability subjects) the psychosocial reintegration was poor. Life for these subjects was impoverished in the extreme, and they could be described as disengaged from life: as a group these subjects did not have any vocational or avocational involvement, were unable to establish significant interpersonal relationships and consequently were highly dependent upon their family. They were also socially isolated, having lost their pretrauma friends, making no new friends and having virtually no social contacts. Other workers have also reported on the impoverished lifestyles that many severely head injured victims experience in the long term, especially for those unable to work..$^{7-9}$

Although a statistically significant relationship was found between the Glasgow Outcome Scale and the level of psychosocial reintegration, the results indicate that, with the exception of the uniform Poor Reintegration of Severe Disability subjects, there was not a one-to-one correspondence between the better categories of the Glasgow Outcome Scale and those of the Psychosocial Disability Scale. The discriminative power of the present Scale is apparent for the Good Recovery and Moderate Disability groups. The Good Recovery subjects are fairly evenly divided between the Substantially Limited and Good Reintegration categories; the Moderate Disability subjects are also evenly divided, but between the Poor and Substantially Limited Reintegration categories.

While life for all Moderate (and Severe) Disability subjects is radically different from the one they knew before the injury, so it is for Good Recovery subjects with Substantially Limited Reintegration (who comprise $30 \%$ of the present series), but the effects of these subjects' ongoing difficulties are often underestimated: their good presentation and relative preservation of social skills mask subtle impairments causing significant disability and handicap. Consequently, they come under considerable pressure from themselves and others (including, not infrequently, doctors and health care workers) to resume their premorbid lifestyles with their premorbid levels of competence. The reality is, however, that these subjects lead a tenuous existence fraught with repeated failures and crises. This subgroup is included along with the groups described by Falvo, Allen and Maki ${ }^{14}$ whose medical conditions cause "invisible disability".

It should be stressed that the initial injury, subsequent medical events and consequent brain impairment are directly related to the level of psychosocial reintegration. Yet it is not just the presence of organic impairments, but a more complex interaction between the types of impairments as they impinge upon the subject's lifestyle. The impairments of the subjects in the present series have been reported separately. ${ }^{15}$ Notwithstanding the fixed nature of impairments, the possibility exists that the level of psychosocial reintegration may be enhanced for some subjects from the better recovered groups. The dichotomous separation of each of the Good Recovery and Moderate Disability groups on the Psychosocial Disability Scale provides a basis for the suggestion that, with some provisos, the Substantially Limited Reintegration of $56 \%$ of Good Recovery subjects and the Poor Reintegration of $50 \%$ of Moderate Disability subjects (in total accounting for $44 \%$ of the series) may be improved, so that these subgroups progress to the next higher category containing the other subjects from the Glasgow Outcome Scale group. The provisos include a concept of rehabilitation for the head injured that goes beyond the acquisition of self care skills and mobility and the provision of and access to extended care services.

The vocational/avocational areas, in particular, play a central role in facilitating enhanced psychosocial reintegration for those Good Recovery and Moderate Disability subjects described above. The restrictive concepts of vocational options commonly encountered in rehabilitation programmes (either return to the workforce or attendance at Sheltered Workshops) are to be discouraged. The present study has replicated the poor employment record reported in other studies ${ }^{4-9} 16$ : one-fifth of the present series (and only $40 \%$ even of the Good Recovery group) was fully employed on the open market at follow up and twice as many Moderate Disability subjects had discontinued as were currently attending a Sheltered Workshop.

Good Recovery subjects clearly require a sophisticated programme relevant to the individual pattern of impairments and premorbid lifestyle; where employment is feasible, the range of supported work re-entry options described in Johnson' ${ }^{17}$ timely study are required. But the neurophysical and/or neuropsychological impairments of the majority of severe head injured victims mean that premorbid types of employment are no longer possible. The $80 \%$ of subjects for whom full employment is an unlikely option, and in particular the $44 \%$ of Good Recovery and Moderate Disability subjects whose reintegration may 
be improved, require rehabilitation in the arts of living independently, establishing friendships and forming leisure pursuits compatible with both their interests and impairments (that is, a remediation programme relevant to the life to which they will be discharged), just as much as they require rehabilitation in basic self care skills and mobility. Following discharge, a range of support services is necessary to maintain the level of psychosocial reintegration, because the impairments of these subjects compromise their ability to take charge of their own existence. It is cause for concern, however, that the need for these types of services has been repeatedly recommended on the basis of the results of other studies, yet Oddy et al $^{9}$ are still able to describe the current status of residential and occupational alternatives as "hopelessly inadequate".

This research has been supported by RADGAC grant number $83 / 3196$ to Professor G A Broe, R L Tate, and J M Lulham. The authors also acknowledge the continued support of Dr G W Carter and Lidcombe Hospital.

\section{Appendix}

Lidcombe Psychosocial Disability Scale

The scale used to classify the subjects' overall level of psychosocial reintegration comprised three parameters: (1) vocational and avocational pursuits; (2) forming and maintaining significant interpersonal relationships; and (3) independent living. Clinical ratings of each subject's performances in the three areas were made in the following manner:

\section{Vocational and avocational pursuits:}

Level 1 (score 1) = Employed (either full time or part-time) at follow up, irrespective of whether subjects had experienced a drop in occupational status or suffered impairments affecting their work skills or were unemployed at the time of follow up although substantial periods of work had occurred since the injury. Level 2 (score 2 ) = Any of: unemployed at the time of follow up but with short and sporadic periods of work since the injury and still seeking employment, attending a Sheltered Workshop or engaged in an avocational programme in lieu of work. Level 3 (score 3 ) $=$ Not working and not engaged in an avocational programme.

\section{Significant interpersonal relationships:}

Level 1 (score 1$)=$ Able to form and maintain significant interpersonal relationships (not restricted to cohabiting relationships). Consideration was given to those subjects who were in the same relationship at the time of follow up as before trauma, as to whether, in the event of a breakdown of that relationship, they would be capable of forming and maintaining a new relationship. Level 2 (score 2) = Experience major difficulties in forming and maintaining significant interpersonal relationships due to impairment resulting from the head injury, such difficulties being manifestly different in type and degree from those normally experienced in maintaining relationships. Level 3 (score 3) = Unable to form significant interpersonal relationships.

\section{Independent living:}

Level 1 (score 1) = Able to live independently, even though emotional supports may be required to do so. Level 2 (score 2) = Experience major difficulties in living independently, but able to live in the community with support services and/or supported accommodation. Level 3 (score 3 ) = Fully dependent upon others for custodial care, provided either by the family or in an institution.

Each subject's scores for the three parameters were summed up and classified into the following categories: Good Reintegration (score 3); Substantially Limited Reintegration (scores 4-6); Poor Reintegration (scores 7-9).

\section{References}

1 Jennett B, Teasdale G, Galbraith S, et al. Severe head injuries in three countries. $J$ Neurol Neurosurg Psychiatry 1977;40:291-8.

2 Thomsen IV. The patient with severe head injury and his family. Scand J Rehab Med 1974;6:180-3.

3 Grosswasser Z, Mendelson L, Stern MJ, Schechter I, Najenson $\mathrm{T}$. Re-evaluation of prognostic factors in rehabilitation after severe head injury. Scand J Rehab Med 1977;9:147-9.

4 Levin HS, Grossman RG, Rose JE, Teasdale G. Longterm neuropsychological outcome of closed head injury. J Neurosurg 1979;50:412-22.

5 Roberts AH. Severe Accidental Head Injury. An assessment of long-term prognosis. London: Macmillan, 1979.

6 Jennett B, Snoek J, Bond MR, Brooks N. Disability after severe head injury: observations on the use of the Glasgow Outcome Scale. J Neurol Neurosurg Psychiatry 1981;44:285-93.

7 Weddell R, Oddy M, Jenkins D. Social adjustment after rehabilitation: a two year follow-up of patients with severe head injury. Pyschol Med 1980;10:257-63.

8 Thomsen IV. Late outcome of very severe blunt head trauma: a 10-15 year second follow-up. J Neurol Neurosurg Psychiatry 1984;47:260-8.

9 Oddy M, Coughlan T, Tyerman A, Jenkins D. Social adjustment after closed head injury: a further followup seven years after injury. $J$ Neurol Neurosurg Psychiatry 1985;48:564-8.

10 Bond MR. Assessment of the psychosocial outcome after severe head injury. In: Porter R, Fitzsimons DW, Eds. Outcome of Severe Damage to the CNS. Ciba Foundation Symposium 34 (new series). Amsterdam: Elsevier, 1975:141-55.

11 Bond MR. Assessment of the psychosocial outcome of severe head injury. Acta Neurochir 1976;34:57-70.

12 Dodwell D. The heterogeneity of social outcome following head injury. J Neurol Neurosurg Psychiatry 1988; 51:833-8.

13 Jennett B, Bond MR. Assessment of outcome after severe brain damage. A practical scale. Lancet 1975;i:480-4.

14 Falvo DR, Allen H, Maki DR. Psychosocial aspects of invisible disability. Rehab Lit 1982;43:2-6.

15 Tate RL, Broe GA, Lulham JM. Impairment after severe blunt head injury: the results from a consecutive series of 100 patients. Acta Neurol Scand 1989;79:97-107.

16 Najenson T, Mendelson L, Schechter I, David C, Mintz N, Groswasser Z. Rehabilitation after severe head injury. Scand Rehab Med 1974;6:5-14.

17 Johnson R. Return to work after severe head injury. Int Disabil Studies 1987;9:49-54. 